\title{
Non-Classical Nucleation of Cerianite at the End Edge of Halloysite Nanotubes
}

\author{
XiangJie CUi ${ }^{1}$, XiAnCAi Lu $^{1 *}$, HuAn LiU ${ }^{1}$ \\ ${ }^{1}$ School of Earth Sciences and Engineering, Nanjing \\ University, Nanjing, Jiangsu 210023, China \\ (MG1829069@smail.nju.edu.cn, *correspondence: \\ xcljun@nju.edu.cn, liuhuan@nju.edu.cn)
}

Clay minerals play important roles in earth surface processes, such as adsorption of metals, nucleation of secondary minerals, and so on. Non-classical nucleation of crystals on basal surface and classical nucleation of metal hydroxide on edge surface of clay minerals have been reported. As a widely distributed member of the kaolinite group, halloysite dominantly appears tubular shape due to the mismatch of tetrahedral and octahedral sheets, which make it an unique clay mineral with highly active surfaces and then irreplaceable geological functions.

In this study, a weathering profile of a REE-rich granite located in the southern China was investigated. In the weathered layer, two types of secondary cerianite with different morphologies were found with high resolution transmission electron microscopy (HR-TEM). One type of cerianite emerges at the end of halloysite nanotubes as nanocrystals with slight orientation, and the other type present as single crystals scattered in the clay aggregations. For the orientated cerianite, the orientation of nanocrystals shows dependence on the attached halloysite tubular. Based on XANES (X-ray absorption near edge structure) analysis of the profile samples, an increase in the ratio of $\mathrm{Ce}^{\mathrm{IV}} /\left(\mathrm{Ce}^{\mathrm{IV}}+\mathrm{Ce}^{\mathrm{III}}\right)$ can be observed from the bottom (parent rock) to the surface layer (completely weathered layer), indicating the cerianite formation can be attributed to the oxidation of $\mathrm{Ce}(\mathrm{III})$ in the weathering processes of granite. By integrating above results, we propose a possible nonclassical nucleation pathway of cerianite in the weathering processes. The released Ce(III) from primary REE-bearing minerals was first adsorbed on the end of halloysite nanotubes because of the higher reactivity of edge surface. Before and/or after the adsorption, Ce(III) was oxidized into $\mathrm{Ce}(\mathrm{IV})$, which need further experimental studies. During the long-term and repeated alternation of wetting and drying occurring in the profile, cerianite polycrystals precipitated with templates of end edge of halloysite, which followed recrystallization and transformation into single large cerianite crystal. This pathway of adsorption-oxidation-nucleation and growth-recrystallization may be a new mechanism for REE enrichment in weathering profiles. 